\title{
Usability Evaluation of the Restaurant Finder Application Using Inspection and Inquiry Methods
}

\author{
Putri Ambarwati* \\ Business Information System \\ Management of Information System \\ Gunadarma University \\ Depok, 16424, Indonesia \\ Putriambar16@gmail.com
}

\author{
Metty Mustikasari \\ Business Information System \\ Management of Information System \\ Gunadarma University \\ Depok, 16424, Indonesia \\ Metty@staff.gunadarma.ac.id
}

\begin{abstract}
Restaurant Finder application is a mobile application that helps users to find restaurants according to their requirements. One of the most well-known and widely used restaurant finder apps is Zomato. Zomato ranks first in the food and delivery category websites from around the world. However, the number of users of a product or application certainly does not guarantee the satisfaction of the user experience of apps. A system that is poorly designed will make it difficult for users, which results in the system being rarely or misused so that the costs to the organization become high and dangerous to the reputation of the company. The purpose of this study was to evaluate the usability of the restaurant finder application using inspection and inquiry methods. Inspection method using the

Enhanced Cognitive Walkthrough method, and for inquiry methods using the User Experience Questionnaire method and the System Usability Scale. The inspection method results identified seven serious problems. Recommendations for improvement based on inspection method are focused on login tasks, reviews, and food promo information. The inquiry methods result identified five aspects that needed improvement. The five aspects consist of novelty, stimulation, learnability, consistency, complexity. The results of this study are expected to provide input and suggestions to the Zomato company for future development of the Zomato app.
\end{abstract}

Keywords: usability evaluation, inspection method, inquiry method, Enhanced Cognitive Walkthrough, System Usability Scale, User Experience Questionnaire

\section{Introduction}

Culinary tourism (CT) is becoming an important subject area, and its development is increasingly documented. Currently, culinary tourism is widely developed into a medium, a vehicle, and a tourist destination (Alonso et al. 2018). According on research conducted by (Stone et al. 2019) most respondents $(80.2 \%)$ agreed that food and drink experiences are important to the trip satisfaction. Positive food and drink experiences influenced a tourist's likelihood of returning to a destination $(81.3 \%$ agreed). The problem of every culinary tourism connoisseur who wants to make a culinary tour visit usually requires information that can support a trip. Some of them are information about culinary destinations and travel routes (Hermawan et al. 2017). Management of the information and proper promotion will help increase business in the culinary field. Providing information about culinary tourism that is easily accessible to the public will provide very good promotional value (Suciyono et al. 2019) . One of them is by using a restaurant finder application that is easily accessible by the public. Restaurant Finder application is a mobile application that helps the users to find the restaurants

* Corresponding Author 
according to their requirements (Parne 2010). One example of an application that is a restaurant finder is Zomato.

Zomato is a restaurant finder application that has gained immense popularity in a relatively short period of time (Sharma and Abdul Waheed 2018). In Zomato, The users could post reviews of the restaurant stating about their experience and visit. The app shows us the existence of air conditioning, Wi-Fi, outdoor seating, smoking area, and whether the restaurant served vegetarian or non-vegetarian and alcohol (Salunkhe and Singh 2019). However, among the several advantages of Zomato, there are still many weaknesses, including the research written by Sihombing et al. (2020) that on the Zomato app, there is no division of halal and non-halal food types. The rating system used by this website has weaknesses because the website provides recommendations based on ratings given by other application users who are unknown to the user, so the level of trust of the rating is very weak (Sihombing et al. 2020). In addition, based on reviews written by Zomato users on Google Playstore, some users have complained that the review system in the Zomato application is not working properly, the location and menu are not updated, the application hangs frequently and others. Furthermore, in October 2020, it was quoted from Tempo.com that Zomato has decided to stop its operations in Indonesia. Even though it has closed its office in Indonesia, Zomato has ensured that its app is still accessible to local users and manages the platform remotely in India (Akbar 2020). The closure of the Zomato office in Indonesia implies that there is a significant decrease in Zomato's users.

Usability has become a central and superior pointer to mobile application design and quality. Looking at the user's perspective, the interface of a mobile application is one of the most significant components, as it constitutes users' main avenue of interaction with the application (Hussain and Mkpojiogu 2016). Several methods exist for evaluating the usability evaluation. They can be mainly categorized as inspection, testing, and inquiry methods (Gulati and Dubey 2012). According to (Gómez et al. 2014) the best alternatives are evaluations conducted by experts (evaluators), also known as Inspection Methods, or evaluations involving users, which are divided into inquiry methods and testing methods depending on the methodology adopted (Gómez et al. 2014). Therefore, this study uses the inspection method for expert-based evaluation and the inquiry method as a representative for user-based evaluation. For the inspection method using the enhanced cognitive walkthrough method and for the inquiry method using a questionnaire. The questionnaires used in this study are the User Experience Questionnaire (UEQ) and the System Usability Scale (SUS).

Previous research conducted by (Scholtes et al. 2020) on Comparison of Formative Evaluation Methods in the Usability Process on the examples of medical app. This study using two expert-based methods and two user-based methods were compared regarding effectiveness in finding issues, the level of detail, and the temporal effort. The results of the study show that the heuristics and the isometrics, both showed a significant advantage regarding the effectiveness and similarity in level of detail and temporal effort. Unfortunately, this research doesn't explain in detail what problems are found in each method and what recommendations the research can provide for the research object.

Based on the description above, research is needed to evaluate the usability of the restaurant finder application using inspection and inquiry method. The restaurant finder application used in this research is the Zomato app. The method used in the inspection method is the Enhanced Cognitive Walkthrough method, while the methods used in inquiry method are the UEQ and SUS. The results of this study are expected to provide input and suggestions to the Zomato company for future development of the Zomato app.

\section{Literature Review}

\section{Zomato App Overview}

Zomato is an increasingly sophisticated mobile application development to help people find restaurants based on certain categories. Zomato can be used via mobile and can also be accessed through the Zomato application. This application makes it easy for people, especially in big cities to find restaurants, coffee shops, live music, and so on from the selected city (Paramitha et al. 2019). 
Unfortunately, as explained above, there are several problems with the Zomato app. In questionnaires distributed online to all respondents, one of the questions is to ask respondents to mention reusability issues in the Zomato application. Some of the problems with the Zomato application experienced by respondents include reviews that do not appear in the review column, the absence of telephone contact from the restaurant, the menu is not updated, the maps are inaccurate, the location of the restaurant is not updated, there is no rating feature per food menu, and etc.

In 2019, a UX researcher from India named Rishav Kumar discovered several user experience problems in Zomato India. Some of the problems include there is the Debug log from the IDE on the notification, searching and viewing restaurants in map view is missing, the removal of the level of foodie feature from the profile has disturbed the foodie ecosystem in the Zomato, and etc. (Kumar 2019). This issue was then assigned to Zomato as a suggestion to the app.

\section{Usability Evaluation}

Usability evaluation focuses on how well users can learn and use a product to accomplish their goals. Usability evaluation is related to user satisfaction to utilization process of those products (Sharfina and Santoso 2017). Usability evaluation assesses the ease of use of a app's functions and how well they enable users to perform their tasks efficiently (Gómez et al. 2014). Usability evaluation can be processed using two different approaches, namely inspection methods (conducted by experts) and inquiry methods (conducted by users). Usability evaluation method classification can be seen in Figure 1.

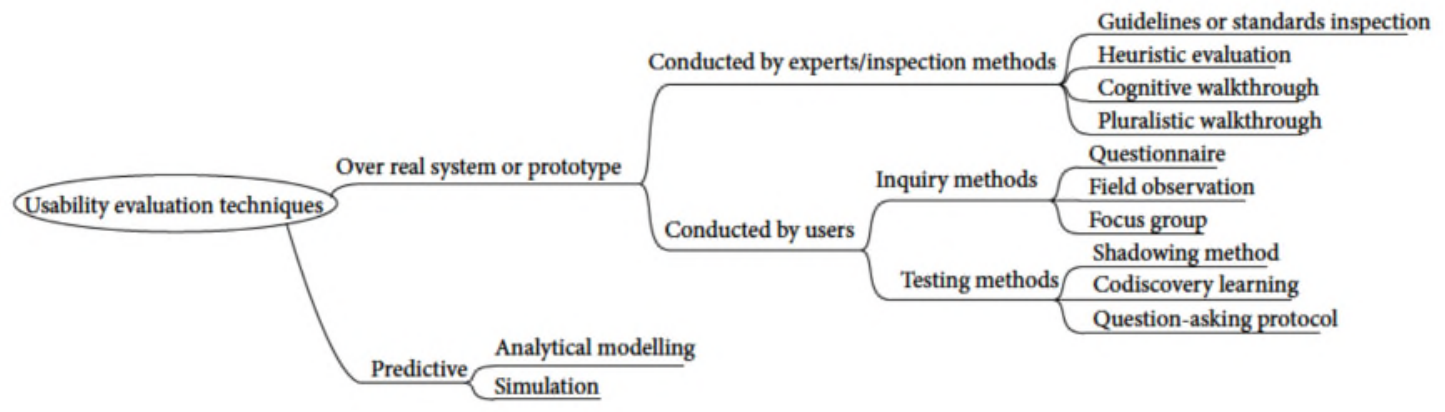

Figure 1. Classification of some usability evaluation techniques (Gómez et al. 2014)

\section{Inspection and Inquiry Methods}

Usability inspection technique focuses on usability experts/ specialists, and sometimes software developers or professionals to examine the usability of user interface design. It is performed before usability test to detect or resolve the obvious problems. Widely used UI methods are Cognitive Walkthrough and Heuristic Evaluation (Satapathy et al. 2014). An inspection entails an evaluator using a set of criteria to identify potential usability problems in an interface. Inspection methods have several advantages and disadvantages. According to (Fernandez et al. 2011). Inquiry or user-based evaluation is an evaluation method to get information about behavior, thoughts, and user interface usage (Cinar 2015). The inquiry method is done by asking users to evaluate a system and provide feedback after interacting with the interface; this feedback is typically achieved via interviews, surveys, or ratings (Unrau and Kray 2019). Inquiry methods focused on gathering subjective data from users, the majority were used in combination with other types of methods such as testing or inspection to perform a more complete evaluation.

\section{Enhanced Cognitive Walkthrough}

Enhanced Cognitive Walkthrough is an alternative version of Cognitive walkthrough 3.0. It was proposed by Bligard and Osvalder (2013) and is used as an analytical approach for predicting and identifying use errors and usability problems (Mahatody et al. 2010). The goal was to develop a method that can better detect and identify given presumptive usability problems in an interface and also provide an overview of which types of problems exist (Bligård and Osvalder 2013). The enhanced cognitive walkthrough is used because it is easy to implement and does not require a lot of time and also concentrates on the ease and understanding of the user with exploration (Ulinuha et al. 2020). However, 
Enhanced Cognitive Walkthrough cannot evaluate the attractiveness, efficiency, and user satisfaction of a product (Bligård and Osvalder 2013). The weakness of the Enhanced Cognitive Walkthrough can be overcome using user-based evaluations. Examples of user-based evaluation methods are the User Experience Questionnaire and the System Usability Scale.

\section{User Experience Questionnaire}

The UEQ is an established and frequently used questionnaire for the evaluation of the UX of interactive products (Hinderks et al. 2018). It should allow the users to express feelings, impressions, and attitudes that arise when experiencing the product under investigation in a very simple and immediate way (Schrepp et al. 2017). UEQ contains six scales of a total of 26 items, consists of attractiveness, efficiency, perspicuity, dependability, stimulation, and novelty (Schrepp 2019). The research questionnaire for UEQ can be seen in the Figure 2.

\begin{tabular}{|c|c|c|c|c|c|c|c|c|c|}
\hline & 1 & 2 & 3 & 4 & 5 & 6 & 7 & & \\
\hline annoying & 0 & 0 & 0 & 0 & 0 & $\mathrm{O}$ & 0 & enjoyable & 1 \\
\hline not understandable & ○ & O & O & O & O & O & 0 & understandable & 2 \\
\hline creative & 0 & 0 & 0 & 0 & 0 & 0 & 0 & dull & 3 \\
\hline easy to learn & O & O & O & O & O & O & O & difficult to learn & 4 \\
\hline valuable & 0 & 0 & 0 & 0 & 0 & 0 & 0 & inferior & 5 \\
\hline boring & O & O & O & O & O & O & O & exciting & 6 \\
\hline not interesting & 0 & 0 & 0 & O & 0 & 0 & 0 & interesting & 7 \\
\hline unpredictable & O & O & O & O & O & $\mathrm{O}$ & O & predictable & 8 \\
\hline fast & $\mathrm{O}$ & 0 & $\mathrm{O}$ & $\mathrm{O}$ & $\mathrm{O}$ & O & 0 & slow & 9 \\
\hline inventive & O & O & O & O & O & O & O & conventional & 10 \\
\hline obstructive & 0 & 0 & O & 0 & 0 & O & 0 & supportive & 11 \\
\hline good & O & O & O & O & O & O & 0 & bad & 12 \\
\hline complicated & 0 & 0 & 0 & 0 & $\mathrm{O}$ & $\mathrm{O}$ & O & easy & 13 \\
\hline unlikable & 0 & $\mathrm{O}$ & 0 & 0 & O & O & O & pleasing & 14 \\
\hline usual & O & 0 & 0 & O & O & O & O & leading edge & 15 \\
\hline unpleasant & O & O & O & O & O & O & O & pleasant & 16 \\
\hline secure & O & 0 & 0 & O & 0 & 0 & 0 & not secure & 17 \\
\hline motivating & 0 & O & 0 & 0 & 0 & O & O & demotivating & 18 \\
\hline meets expectations & O & O & O & O & O & 0 & 0 & does not meet expectations & 19 \\
\hline inefficient & 0 & 0 & 0 & 0 & 0 & 0 & 0 & efficient & 20 \\
\hline clear & O & 0 & O & 0 & O & O & O & confusing & 21 \\
\hline impractical & O & O & O & O & 0 & O & O & practical & 22 \\
\hline organized & 0 & O & O & 0 & O & O & 0 & cluttered & 23 \\
\hline attractive & $\mathrm{O}$ & O & O & O & 0 & $\mathrm{O}$ & O & unattractive & 24 \\
\hline friendly & O & O & O & O & 0 & 0 & 0 & unfriendly & 25 \\
\hline conservative & O & O & O & O & O & O & ○ & innovative & 26 \\
\hline
\end{tabular}

Figure 2. UEQ Questionnaire (Schrepp 2019)

\section{System Usability Scale}

The SUS was developed in 1986 by John Brooke and its value is to provide a single reference score for participants' view of a product's usability (Sharfina and Santoso 2017). SUS is an inexpensive, yet effective tool, for assessing the usability of a product, as well as a wide range of user interfaces, including standard operative system based software interfaces, web pages, cell phones, landline phones, speech systems, or video delivery hardware and software (Martins et al. 2015).

A recent study shows that it can be divided into two sub-scales of usability and learnability: usable (item 1, 2, 3, 5, 6, 7, 8, and 9) and learnable (item 4 and 10) (Sharfina and Santoso 2017). Other attributes, such as perceived complexity (Item 2), perceived ease-of-use (Item 3), perceived consistency (Item 6), perceived learnability (Item 7), and confidence-in-use (Item 9) do appear in the SUS (Lewis and Sauro 2018). The ten questions are closely related and are employed for the comprehensive evaluation of a product. A higher SUS score indicates better product usability (Liang et al. 2018). The Items of System Usability Scale can be seen in the Table 1. 
Table 1. Question items of the System Usability Scale

\begin{tabular}{|c|l|}
\hline No & \multicolumn{1}{|c|}{ Items } \\
\hline 1. & I think that I would like to use this system. \\
\hline 2. & I found the system unnecessarily complex. \\
\hline 3. & I thought the system was easy to use. \\
\hline 4. & $\begin{array}{l}\text { I think that I would need the support of a technical person to be able to } \\
\text { use this system. }\end{array}$ \\
\hline 5. & I found the various functions in the system were well integrated. \\
\hline 6. & I thought there was too much inconsistency in this system. \\
\hline 7. & $\begin{array}{l}\text { I would imagine that most people would learn to use this system very } \\
\text { quickly. }\end{array}$ \\
\hline 8. & I found the system very cumbersome to use. \\
\hline 9. & I felt very confident using the system. \\
\hline 10. & $\begin{array}{l}\text { I needed to learn a lot of things before I could get going with this } \\
\text { system. }\end{array}$ \\
\hline
\end{tabular}

\section{Methodology}

\section{Research Subject}

The research subjects divided into two types consist of evaluators and end-users. Evaluator is for someone who knows deeper about usability and user experience of apps, and end-users are people who use the Zomato app. The number of evaluators used was five people. Rahadiasta et al. (2019) said that the recommended participants for usability evaluation in qualitative case studies were 5 people. If the research involves more than one user group or category, the participants can be adjusted into 3 to 4 people per group or category (Rahadiasta et al. 2019). The evaluator criteria used in this study are someone who has a background in computer education or digital design, has knowledge of UI / UX Design, Human-Computer Interaction, and usability testing, and has experience working in the UI / UX field.

For inquiry method, the number of respondents is determined using the Lemeshow Formula. Based on the Lemeshow formula, the result obtained is 96.04 or 97 respondents. That means in this study the researcher must take data from a sample of at least 100 respondents. This sampling was shown to people who were over 17 years old and had used the Zomato application.

\section{Research Design}

The research methods are a sequence of research steps that will be carried out starting from the literature study. At this stage, it is done by reading related research through journals, articles, papers, internet, and reference books. The second is preparing for evaluation, at this stage, it is used to identify the data needed for research. The next process is data collection, data collection on the Enhanced Cognitive Walkthrough method is by conducting interviews and questionnaires with the evaluator about the usability problems that exist in the task scenario. Meanwhile, in the data collection stage for UEQ and SUS, the questionnaires were distributed online via Google form. The next process is Data Analysis, at this stage, the data that has been collected from the evaluators and respondents will be analyzed. In the enhanced cognitive walkthrough, the information gathered from the evaluators is organized into a matrix to emphasize various aspects of the analysis. Meanwhile, In the User Experience Questionnaire and System Usability Scale, the data collected will be tested for validity and reliability first. After that, UEQ data will be processed using UEQ analysis tools and SUS data will be processed using weighting the SUS score. The last process is the recommendation. At this stage, for the Improvement of the Zomato app, the result of the data analysis had come to conclusions that were used as a reference to propose a recommendation for improvement of Zomato app. The research design can be seen in Figure 3. 


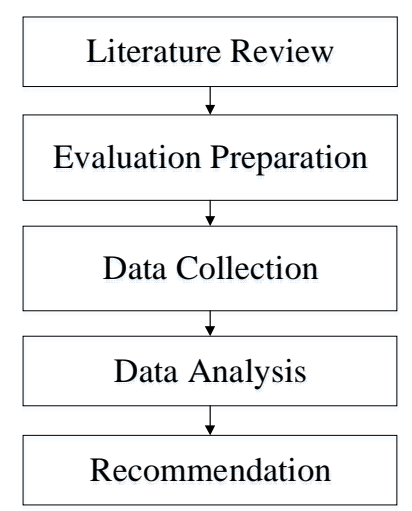

Figure 3. Research Design

\section{Results}

\section{Enhanced Cognitive Walkthrough}

The first stage of the enhanced cognitive walkthrough is to define the task scenario, then determine the task scenario specification using HTA. The task scenario can be seen in Table 2. Grade 1 is the most important task or must be done, which means that other tasks cannot be done if grade 1 tasks have not been done. Grade 2 is the second important task that must also be done. Grade 3 is a task that is not very important but supports users in using the application. Grade 4 and Grade 5 are the least important tasks.

Table 2. Task Scenario of the Enhanced Cognitive Walkthrough

\begin{tabular}{|c|l|c|}
\hline Num & \multicolumn{1}{|c|}{ Task Scenario } & Grading Task \\
\hline 1. & Login to the Zomato app & 1 \\
\hline 2. & Look at the restaurant menu & 2 \\
\hline 3. & Find Out Food Promos & 4 \\
\hline 4. & Write a review about the restaurant & 3 \\
\hline 5. & Filtering the restaurant & 3 \\
\hline 6. & Edit Profile & 5 \\
\hline
\end{tabular}

In the Enhanced Cognitive Walkthrough method, evaluators are asked to answer two levels of analysis, namely analysis of functions and analysis of operations. Then the participants will answer the level 1 question (function analysis) according to the hierarchical order of the HTA (top to bottom). And at the lowest level participants will answer new questions at level 2 (analysis of operations).

The following are questions that must be answered at level 1 (analysis of function):

1. Will the user know that the evaluated function is available?

2. Will the user be able to notice that the function is available?

3. Will the user associate the clues with the function?

4. Will the user get sufficient feedback when using the function?

5. Will the user get sufficient feedback to understand that the function has been fully performed?

Then the participants will answer these questions in order of the Hierarchy Task Analysis (HTA) from top to bottom. The following are questions that must be answered at level 2 (analysis of operations):

1. Will the user try to achieve the right goals of the operation?

2. Will the user be able to notice that the action of the operation is available?

3. Will the user associate the action of the operation with the right goal of the operation?

4. Will the user be able to perform the correct action?

5. Will the user get sufficient feedback to understand that the action is performed, and the goal is achieved? 
The above questions will be answered by the respondent and then given a value between 1 and 5 . These values will represent the respondent's level of success in carrying out each task as shown in Table 3.

Table 3. Level of Success

\begin{tabular}{|c|l|l|}
\hline Grade & Grade in Words & \multicolumn{1}{c|}{ Explanation } \\
\hline 5 & Yes & A Very Good Chance of Success \\
\hline 4 & Yes, probably & Probably Successful \\
\hline 3 & Do not Know & Impossible to decide if success or not \\
\hline 2 & No, uncertain & Small chance of Success \\
\hline 1 & No & A Very small chance of success \\
\hline
\end{tabular}

After grading the level of success, then the problems are put into different categories. Based on the appearance and tasks the respondent performed in the walkthrough, several different types of problems can be defined (Table 4).

Table 4. Problem Type

\begin{tabular}{|l|l|}
\hline Problem Type & \multicolumn{1}{c|}{ Explication } \\
\hline User (U) & $\begin{array}{l}\text { The problem is due to the user's experience and knowledge, possibly } \\
\text { because the user is accustomed to different equipment. }\end{array}$ \\
\hline Hidden (H) & $\begin{array}{l}\text { The interface gives no indications that the function is available or how } \\
\text { it should be used. }\end{array}$ \\
\hline Text and Icon (T) & $\begin{array}{l}\text { Placement, appearance and content can easily be misinterpreted or not } \\
\text { understood. }\end{array}$ \\
\hline Sequence (S) & Functions and operations have to be performed in an unnatural sequence. \\
\hline $\begin{array}{l}\text { Physical } \\
\text { Demands (P) }\end{array}$ & $\begin{array}{l}\text { The interface sets too high demands on users' physical speed, motoric } \\
\text { skill and force. }\end{array}$ \\
\hline Feedback (F) & $\begin{array}{l}\text { The interface gives unclear indications of what the user is } \\
\text { doing or has done. }\end{array}$ \\
\hline
\end{tabular}

If the level of seriousness of the problem is between 1 until 4, it means that there is a usability problem in the task. So that further explanation is needed about the problems found by the evaluator. This is to get a deeper knowledge about the problem. From the questionnaire filled out by the evaluator, data on the seriousness of the problem and the types of problems of each task will be obtained. The data will be processed into the matrix. The goal is to find usability problems that arise using the five matrices in the ECW method, which consists of:

1. Matrix A: Problem seriousness versus task importance (PS vs TI)

2. Matrix B: Problem type versus problem seriousness (PT vs PS)

3. Matrix C: Problem type versus task importance (PT vs TI)

4. Matrix D: Problem seriousness versus task number (PS vs TN)

5. Matrix E: Problem type versus task number (PT vs TN).

\section{User Experience Questionnaire}

UEQ data will be processed by entering the results of the questionnaire data into the UEQ analysis tool. The UEQ count tool was created using a Microsoft Excel tool and can be downloaded together with a questionnaire file. The 3 stages of UEQ's assessment in terms of the Data Analysis Tool, namely:

a. Data Transformed

Respondent result data entered into UEQ's calculating tool undergoes a data transformation process, namely a randomized order of values in a questionnaire to minimize the tendency for answers. Respondents rated each item on a 7-point Likert scale. Respondents' answers were given a scale from -3 (completely agree with negative terms) to +3 (completely agree with positive terms). Half of the items started with positive terms, and the others with negative terms (in random order). The transformed data will produce an average value for each respondent. Then the data will be grouped based on a predetermined scale, namely the scale of Attractiveness, Efficiency, Perspicuity, Dependability, Stimulation, and Novelty. 
b. Main Results

The result of data transformation is managed to get the main result. The main result is the UEQ result which will serve as a guideline for the next calculation, namely the Benchmark Data Set. Here the overall scale and the scale of assumptions (Attractiveness, Pragmatic and Hedonic quality) are determined by calculating the mean and variance of the average data conversion results that have been obtained at the specified scale. The determination of the mean per scale results has a standard, namely the average impression value between -0.8 and 0.8 is a normal evaluation value, if the value $>0.8$ is a positive evaluation, and if the value $<-0.8$ is a negative evaluation.

c. Benchmark Data Set

UEQ uses the Benchmark standard. This data set contains data from 20190 persons from 452 studies concerning different products (business software, web pages, webshops, social networks). Benchmark standard calculations are used to describe the comparison of the quality of the Zomato application with 246 products from UEQ evaluation data.

\section{System Usability Scale}

After the data is tested for validity and reliability, the data will be entered into Microsoft Excel to be processed. The data will be calculated using a weighted SUS score. However, there are rules in calculating the weighting of the SUS score. The following are the rules for weighting the scores on the questionnaire:

1. For every odd-numbered question, the final score is the result of subtracting the user's score (x) minus 1 .

2. For every even-numbered question, the final score is the result of subtracting results from 5 minus the user's score $(\mathrm{x})$.

3. The weighting of the SUS score is obtained from the sum of the overall user scores multiplied by 2.5 .

After that, the SUS score of each respondent is calculated the average score by adding the overall score and divided by the total number of respondents. The results of the calculation are divided into 5 Letter Grades from A, B, C, D, and F with a choice of ratings of Excellent, Good, OK, Poor, and Awful.

\section{Data Analysis}

\section{Enhanced Cognitive Walkthrough}

The matrices in ECW are employed to present an overview picture of problems in the interface. These types of matrices can also be employed to compare different interfaces and see which interface has the least serious problems or whether there are different problem types between interfaces. Problems that are considered serious for important tasks should then be further investigated to decide if they are also potential usability problems in real situations of handling. The results of the user experience evaluation using the enhanced cognitive walkthrough method explained that in general there were not many serious problems affecting the main task of the Zomato application. The number of problems identified by the evaluators was 114 problems. However, several evaluators identified the same problem. If removing data duplications, then left 42 unique problems. Of the 42 problems identified, 7 of them are serious problems based on the matrixes. The following is a summary of the matrices that have created.

\section{a. Matrix A}

Matrix A shows the general condition of the interface. In general, most of the problems in the interface are not serious, serious problems were found on the login screen, OTP Code, and mismatched button placement.

b. Matrix B

Matrix B shows the overall problems with the interface. Generally, the most problems in the Zomato app are problems in the fourth level of seriousness. It means that most of the problems in the Zomato app are problems that do not have a direct impact on the main function of the application. However serious problems are also found in this app. these problems are at the second seriousness level with problem types consisting of Hidden (H), Text and Icon (T), Sequence (S), 
and Feedback (F). So, it can conclude most of the problems are related to reviews, such as reviews that cannot be fully viewed, reviews that are lost when the number of stars is changed, and reviews that do not appear in the review list. Thus, the task of writing reviews on restaurants needs to be examined further.

c. Matrix C

Matrix $\mathrm{C}$ to shows which problems are most important to rectify. The most important problems to fix based on the $\mathrm{C}$ matrix table are problems that exist in task importance one and two with the user (U), Text and Icon (T), Physical Demand (P), and Feedback (F) problem types.

d. Matrix D

Matrix D shows which task had the most problems. Based on the D matrix that has been made, the task that has the most problems is the fourth task number, which is writing restaurant reviews, and then the fifth task number, which is doing restaurant filtering.

e. Matrix E

Matrix E shows which problems are most common in the task. In general, the most common problems are problems with the Text and Icon (T) type. It means most of the issues regarding placement, appearance, content, and color that can easily be misinterpreted or not understood.

\section{f. User Experience Questionnaire}

User Experience evaluation of the restaurant finder application using the User Experience Questionnaire shows that users get enough of what they want in terms of attractiveness, system functionality, and in terms of appearance that makes users comfortable. The results of UX evaluation shows that the aspect that must be examined is the novelty aspect which gets a score of 0.683 . It indicates that the user has not found the novelty in the offered app. The result of the UEQ benchmark also shows that the results from the Novelty aspect are close to below average. The scale denoting the novelty aspect consist of Creative to Dull, Inventive to Conventional, Usual to Leading Edge, and Conservative to Innovative. These scales indicate that respondents consider the Zomato app to be quite monotonous, conventional, usual, and conservative. It means an upgrade to the Zomato app is needed.

Besides, when viewed based on the results of the Hedonic Quality and Pragmatic Quality groups. Pragmatic Quality is a positive evaluation result and Hedonic Quality is a neutral evaluation. The assessment of hedonic quality comes from the aspects of stimulation and originality. In Figure 4, 2 out of 4 items in the stimulation aspect get a neutral result instead of a positive result. It means the stimulation aspect needs to be examined further. Two question items from the Stimulation aspect that get normal results are Boring to Exciting and Motivating to Demotivating. 


\begin{tabular}{|c|c|c|c|c|c|c|c|}
\hline Item & Mean & Variance & Std. Dev. & No. & Left & Right & Scale \\
\hline 1 & 个 1.4 & 1.0 & 1.0 & 100 & annoying & enjoyable & Attractiveness \\
\hline 2 & 个 1.7 & 0.9 & 0.9 & 100 & not understandable & understandable & Perspicuity \\
\hline 3 & $\Rightarrow 0.6$ & 1.1 & 1.1 & 100 & creative & dull & Novelty \\
\hline 4 & 个 1.4 & 1.3 & 1.1 & 100 & easy to learn & difficult to learn & Perspicuity \\
\hline 5 & 个) 1.0 & 1.1 & 1.1 & 100 & valuable & inferior & Stimulation \\
\hline 6 & $\Rightarrow 0.8$ & 0.8 & 0.9 & 100 & boring & exciting & Stimulation \\
\hline 7 & 个 1.0 & 0.8 & 0.9 & 100 & not interesting & interesting & Stimulation \\
\hline 8 & 个 1.1 & 1.2 & 1.1 & 100 & unpredictable & predictable & Dependability \\
\hline 9 & 个 1.0 & 1.1 & 1.0 & 100 & fast & slow & Efficiency \\
\hline 10 & $\Rightarrow 0.7$ & 0.8 & 0.9 & 100 & inventive & conventional & Novelty \\
\hline 11 & 个 1.6 & 0.9 & 1.0 & 100 & obstructive & supportive & Dependability \\
\hline 12 & 会 1.7 & 0.9 & 0.9 & 100 & good & bad & Attractiveness \\
\hline 13 & î 1.5 & 1.0 & 1.0 & 100 & complicated & easy & Perspicuity \\
\hline 14 & 令 1.4 & 0.8 & 0.9 & 100 & unlikable & pleasing & Attractiveness \\
\hline 15 & $\Rightarrow 0.7$ & 1.1 & 1.1 & 100 & usual & leading edge & Novelty \\
\hline 16 & 个 1.4 & 0.8 & 0.9 & 100 & unpleasant & pleasant & Attractiveness \\
\hline 17 & 个) 1.2 & 0.9 & 1.0 & 100 & secure & not secure & Dependability \\
\hline 18 & $\Rightarrow 0.8$ & 0.6 & 0.8 & 100 & motivating & demotivating & Stimulation \\
\hline 19 & 个 1.0 & 0.9 & 0.9 & 100 & meets expectations & does not meet expectations & Dependability \\
\hline 20 & 1.4 & 0.8 & 0.9 & 100 & inefficient & efficient & Efficiency \\
\hline 21 & 个 1.4 & 1.1 & 1.1 & 100 & clear & confusing & Perspicuity \\
\hline 22 & 个 1.5 & 0.9 & 0.9 & 100 & impractical & practical & Efficiency \\
\hline 23 & 个 1.2 & 0.7 & 0.8 & 100 & organized & cluttered & Efficiency \\
\hline 24 & 个 1.3 & 1.0 & 1.0 & 100 & attractive & unattractive & Attractiveness \\
\hline 25 & 个 1.3 & 0.9 & 0.9 & 100 & friendly & unfriendly & Attractiveness \\
\hline 26 & $\Rightarrow 0.7$ & 0.9 & 1.0 & 100 & conservative & innovative & Novelty \\
\hline
\end{tabular}

\section{Figure 4. The result of UEQ}

\section{g. System Usability Scale}

The System Usability Scale can be used as an evaluation tool for evaluating software interfaces that are measured and structured accurately. Based on the results of the Usability evaluation using the System Usability Scale (Figure 5), the Zomato app gets a score of 71 with a "Good" rating, Letter Grade "C", and included in the "Acceptable" category. From these results, it can be concluded that the Zomato application fulfills the Usability element, although there are still some weaknesses. When viewed on a per-item basis, the tenth item (I needed to learn a lot of things before I could get going with this app) has the highest number of negative scales with a total of 93 answers from 100 respondents. The second position with the highest number of negative scales is the sixth item (I thought there was too much inconsistency in this app) with a total score of 92. The third position is the second and eighth items because they both have 90 negative scales. The negative scale is calculated from the sum of the scores 1,2 , and 3 on the weighted SUS score.

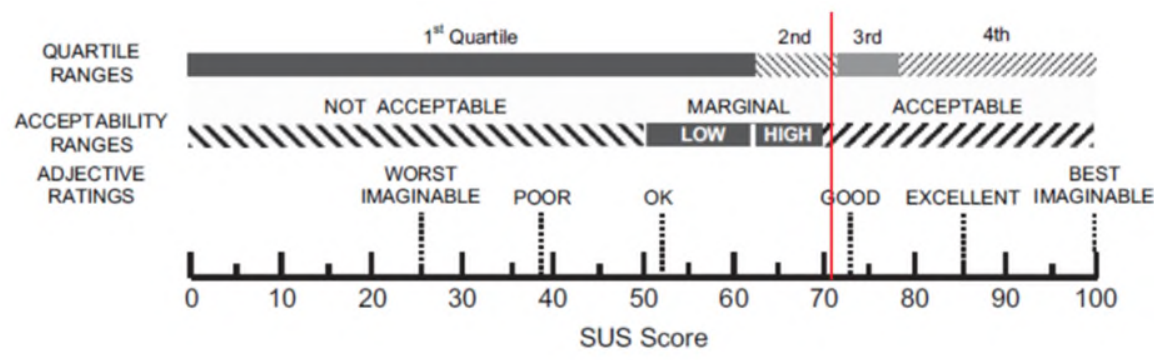

Figure 5. SUS Score Interpretation Scale (Bangor et al. 2008)

\section{Inspection and Inquiry Methods}

At this stage, it will explain and compare the results of the evaluation from inspection and inquiry methods. This study compared the 3 methods in terms of the number of identified usability problems, problem description, and level of details. Comparing the number of usability problems that have been done before in research conducted by (Khajouei et al. 2017). To compare the number of usability 
problems is to count the number of problems identified. For inquiry methods cases, the author breaks down the results of the evaluation to get the reason why the evaluation results cannot achieve the maximum results. After that, the results of the number of usability problems spelled out in the problem description.

To compare the level of details using the theory employed in the research conducted by Scholtes et al. (2020). Scholtes et al. (2020) said the authors can determine the level of detail. The level of details was defined as low, if the method reflects only the opinion of the test person, as moderate, if the method also describes the problem, and as high, if it also describes the possible location effects of the problem (Scholtes et al. 2020). Table 5 shows the evaluation results between inspection and inquiry methods.

Table 5. Evaluation results

\begin{tabular}{|c|c|c|c|}
\hline \multirow[t]{2}{*}{ Categories } & Inspection Method & \multicolumn{2}{|c|}{ Inquiry Method } \\
\hline & ECW & UEQ & SUS \\
\hline $\begin{array}{l}\text { Evaluation } \\
\text { Results }\end{array}$ & $\begin{array}{l}\text { The evaluation results were } \\
\text { based on matrix A. In general, } \\
\text { most of the problems in the } \\
\text { interface are not so serious and } \\
\text { do not affect the main function } \\
\text { of the app. But need to be } \\
\text { considered for the perfection of } \\
\text { the app. }\end{array}$ & $\begin{array}{l}\text { Most of the aspects } \\
\text { showed positive } \\
\text { evaluation results. }\end{array}$ & $\begin{array}{l}\text { The evaluation results } \\
\text { get a "Good" rating, } \\
\text { Letter Grade "C", and } \\
\text { were included in the } \\
\text { "Acceptable" } \\
\text { category. }\end{array}$ \\
\hline $\begin{array}{l}\text { Number of } \\
\text { Usability } \\
\text { Problems }\end{array}$ & $\begin{array}{l}114 \text { problems identified. If } \\
\text { remove data duplications, then } \\
\text { left } 42 \text { unique problems. Of the } \\
42 \text { problems, } 7 \text { of them are } \\
\text { serious problems based on the } \\
\text { matrixes. }\end{array}$ & $\begin{array}{l}\text { Two of the six } \\
\text { aspects of UEQ } \\
\text { need to be } \\
\text { examined further, } \\
\text { namely the } \\
\text { Novelty aspect and } \\
\text { Stimulation aspect. }\end{array}$ & $\begin{array}{l}4 \text { out of } 10 \text { question } \\
\text { items have the greatest } \\
\text { number of negative } \\
\text { scales. }\end{array}$ \\
\hline $\begin{array}{l}\text { Problem } \\
\text { Description }\end{array}$ & $\begin{array}{l}\text { 1. It will be more familiar if the } \\
\text { first page contains login and } \\
\text { register options ( } 3 \mathrm{U}) \text {. } \\
\text { 2. Several buttons on the login } \\
\text { clipped ( } 3 \mathrm{~T} \text { ) } \\
\text { 3. There is an overlapping button } \\
\text { (3T) } \\
\text { 4. Promo information that is } \\
\text { difficult to find ( } 3 \mathrm{H}) \\
\text { 5. Reviews do not appear in the } \\
\text { review list ( } 2 \mathrm{~F}) \\
\text { 6. Reviews that have been } \\
\text { written will be lost if we make } \\
\text { changes to the star rating ( } 2 \mathrm{~S} \text { ) } \\
\text { 7. When users write long } \\
\text { reviews, they can't be seen } \\
\text { completely ( } 2 \mathrm{~T})\end{array}$ & $\begin{array}{l}\text { Novelty Aspect: } \\
\text { - Creative to } \\
\text { Dull } \\
\text { - Inventive to } \\
\text { Conventional } \\
\text { - Usual to } \\
\text { Leading Edge } \\
\text { - Conservative to } \\
\text { Innovative } \\
\text { Stimulation } \\
\text { Aspect: } \\
\text { - Boring to } \\
\text { Exciting. } \\
\text { - Motivating to } \\
\text { Demotivating }\end{array}$ & $\begin{array}{l}10^{\text {th }} \text { item: I needed to } \\
\text { learn a lot of things } \\
\text { before I could get } \\
\text { going with this app. } \\
6^{\text {th }} \text { item: I thought } \\
\text { there was too much } \\
\text { inconsistency in this } \\
\text { app. } \\
2^{\text {nd }} \text { item: I found the } \\
\text { system unnecessarily } \\
\text { complex. } \\
8^{\text {th }} \text { item: I found the } \\
\text { system } \\
\text { cumbersome to use. }\end{array}$ \\
\hline $\begin{array}{l}\text { Level of } \\
\text { Details }\end{array}$ & High & Low & Low \\
\hline
\end{tabular}


In general, the evaluation results show that the application is quite good in terms of usability. Also, it doesn't find any significant problems in the application. When viewed from the side of effectiveness. Effectiveness was measured by counting the number of errors that occur while the evaluator completes the task. The number of errors identified was 42 out of 195 questions in inspection method. It means the percentage of effectiveness is $78.46 \%$. Thus, it can be concluded that this restaurant finder application can be said to be quite effective.

In the inquiry method results, five aspects need to be improved from the Zomato application. Two aspects come from the evaluation results of the UEQ, namely novelty and stimulation. Three aspects come from the evaluation results of the SUS, namely learnability, consistency, and complexity. The learnability aspect is based on the tenth question on the SUS. The consistency aspect is based on the sixth question on the SUS. The complexity aspect is based on the second and eighth questions on the SUS. Based on the UEQ evaluation results, the application gets a positive evaluation. Meanwhile the SUS evaluation results, the application gets a 'Good' rating, a ' $\mathrm{C}$ ' letter grade, and included in the 'Acceptable' category. Thus, it can be concluded that user satisfaction towards the restaurant finder application is good.

\section{Implications}

Based on the results of the inspection method, recommendations for improvement the Zomato app are focused on login tasks, reviews, and food promo information. Besides, most of the problems that exist in this restaurant finder application were related to text and icon problems where there are many placements, appearance, content, and buttons that can be easily misinterpreted or not understood by users. Improvement was done by making a prototype of the login screen, main menu, and review screen. Meanwhile, based on inquiry results, recommendations for improvement are focused on aspects of novelty, stimulation, learnability, consistency, and complexity. Thereby, the focusing of problems between five attributes can be more optimal to the usability side and improve user experience to Zomato Application. The following is a recommendation improvement for any serious problems identified using the inspection method.

\section{Unfamiliar Login Page}

Some users may be unfamiliar or inexperienced with the type of login. Maybe it would be better if the first page contains the options for login and registration because it is more familiar to users instead of contains the type of login via email and phone number.

\section{Improper placement of buttons}

Although it seems trivial, improper placement of buttons is one of the important problems that need to be fixed. Improper placement of buttons needs to be corrected so that users are not confused and do not choose the wrong button (Figure 6). One of the contents of the usability guidelines made by (Shitkova et al. 2015) is place content in the central part of the screen. Placement of content that is leaning to the right or left can make the interface look unattractive; thus, the design should be improved as shown in Figure 7. 


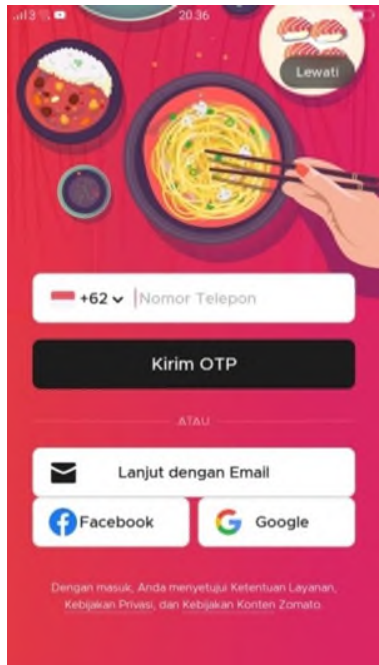

Figure 6. Login screen

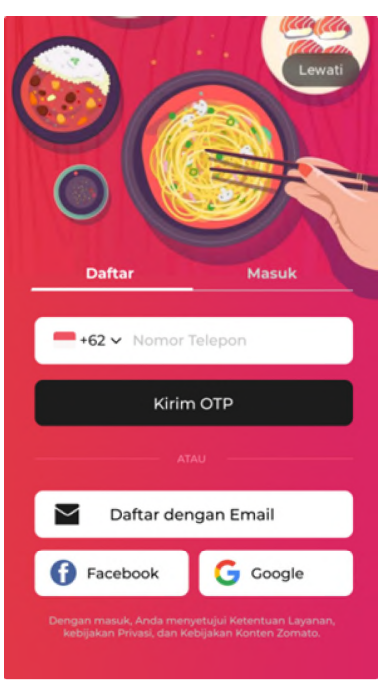

Figure 7. Design improvement of Figure 6

\section{Improper placement of buttons}

Although it seems trivial, improper placement of buttons is one of the important problems that need to be fixed. Improper placement of buttons needs to be corrected so that users are not confused and do not choose the wrong button. One of the contents of the usability guidelines made by Shitkova et al. (2015) is to place content in the central part of the screen. Placement of content that is leaning to the right or left can make the interface look unattractive. Figure 8 is an example of improper button placement in the Zomato app. In Figure 8, the button name is too long, and the buttons are overlapping which makes the buttons difficult to read; thus, the design improvement can be seen in Figure 9.

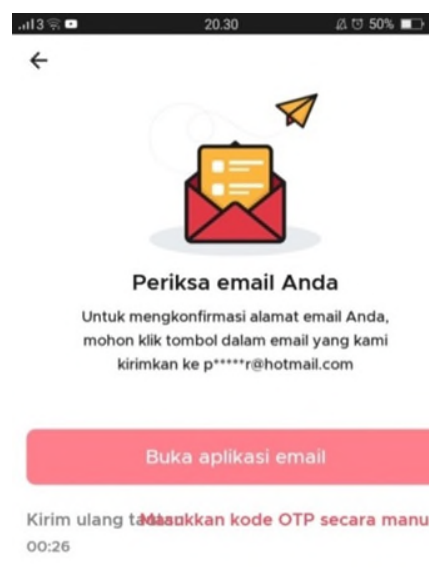

Figure 8. Improper placement of button

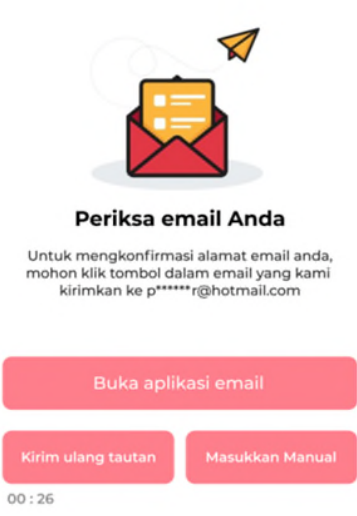

Figure 9. Design improvement of Figure 8

4. Promo's button is very hard to find.

The promos button is difficult for users to find. In the main menu of the Zomato app, users need to scroll down many times to find the promo button. The promo should be an interesting thing to see for the first time. It would be better if the promotion button is placed in a place that is easily visible to the user. In line with contents of the usability guidelines made by Shitkova et al. (2015) said that important pages should be reachable from the home page. 
5. Reviews that cannot be fully viewed

When a user writes a review that is longer than four lines, the review is not scrollable. So, the review cannot be seen in full. Users will find it difficult to see all the reviews that have been written.

6. Reviews that have been written will be lost if changes the star rating.

When a user has written a review and wants to change the number of stars, the review that has been written will disappear and must write a review again. It makes users must rewrite the review. So, maybe some users will discourage to write a review again. It would be better when users change their star rating, the reviews that have been written are not deleted.

\section{No Feedback in Reviews}

After giving a review, the review that the evaluator wrote did not appear in the review list even after the evaluator tried it twice, the review still did not appear. Application response to the reviews was bad. This is a quite serious problem and needs to be fixed immediately as it can discourage users from writing restaurant reviews.

\section{Discussion}

According to Mahatody et al. (2010), the Cognitive Walkthrough method has undergone nine changes and the last change is the Enhanced Cognitive Walkthrough version. Thus, it can be said that the Enhanced Cognitive Walkthrough method is the latest version of the Cognitive Walkthrough method. Enhanced Cognitive Walkthrough has several advantages over its predecessors, namely (i) ECW has a high level of perspective in user interface evaluation, which can be manifested. (ii) Descriptions of success or failure yield adequate information about the difference in problem severity between different operations. (iii) The general description of the results can be explained well because of the matrices. However, among its strengths, the Enhanced Cognitive Walkthrough also has weaknesses including the inability of the method to evaluate user satisfaction, user attractiveness, efficiency, etc. (Bligård and Osvalder 2013). The weakness of the Enhanced Cognitive Walkthrough can be overcome using userbased evaluations. Examples of user-based evaluation methods are the UEQ and the SUS.

The results of the evaluation of the three methods show similar results, where the Zomato application is quite good in terms of usability, although there are still some weaknesses. These weaknesses are explained in the problem description in Table 5. Each method identifies a different problem. Therefore, all of the methods are interrelated and complement each other. This can be a good recommendation for Zomato company regarding usability issues in their application because the problem is not only seen from the point of view of the evaluator but also the users. This is in line with the statement by Jaspers (2009), each method both inspection and inquiry methods have its own advantages and disadvantages, and no single method reveals significant results which show that it is very effective in all circumstances. A complementary combination of usability analysis techniques should preferably be used because the collective application will be more powerful than those used separately.

\section{Conclusion}

Research on usability evaluation of restaurant finder applications using inspection and inquiry methods has been done. The restaurant finder application used in this study is the Zomato app. This study uses two types of usability evaluation methods, namely Inspection and Inquiry methods. The number of methods used in this study was three methods, namely Enhanced Cognitive Walkthrough, UEQ, and SUS. In the evaluation results of the Enhanced Cognitive Walkthrough method, there were no significant problems that could interfere with the main functions of the application. The number of problems identified by the evaluators was 114 problems. However, several evaluators identified the same problem. If removing data duplications, then left 42 unique problems. Of the 42 problems identified, 7 of them are serious problems based on the matrixes. The results of the Usability evaluation using the System Usability Scale, the Zomato app gets a score of 71 with a "Good" rating, Letter Grade "C", and included in the "Acceptable" category. From these results, it can be concluded that the Zomato 
application fulfills the Usability element, although there are still some weaknesses. For user Experience evaluation of the restaurant finder application using the User Experience Questionnaire shows that users get enough of what they want in terms of attractiveness, perspicuity, efficiency, dependability, stimulation, novelty and in terms of appearance that makes users comfortable.

The results of the usability evaluation of the restaurant finder application using inspection and inquiry methods are that the Zomato application is good, but there are still several tasks that need to be improved for the perfection of the application. Based on the inspection method, recommendations for improvements are focused on login tasks, reviews, and food promo information. Besides, based on inquiry methods, recommendations for improvement also need to be emphasized on aspects of novelty, stimulation, learnability, consistency, and complexity. The limitation of this study is that this study cannot compare the attributes for each method. Future research can use methods that have the same attributes, so that the results of the comparison can be more accurate.

\section{References}

Akbar, C. 2020. "Zomato Leaves Indonesia; App Remains Accessible." (https://en.tempo.co/read/1397860/zomato-leaves-indonesia-app-remains-accessible).

Alonso, A. D., Kok, S., and O’Brien, S. 2018. "Sustainable Culinary Tourism and Cevicherías: A Stakeholder and Social Practice Approach," Journal of Sustainable Tourism (26:5), Taylor \& Francis, pp. 812-831 (doi: 10.1080/09669582.2017.1414224).

Bangor, A., Kortum, P. T., and Miller, J. T. 2008. "An Empirical Evaluation of the System Usability Scale," International Journal of Human-Computer Interaction (24:6), pp. 574-594 (doi: 10.1080/10447310802205776).

Bligård, L. O., and Osvalder, A. L. 2013. "Enhanced Cognitive Walkthrough: Development of the Cognitive Walkthrough Method to Better Predict, Identify, and Present Usability Problems," Advances in Human-Computer Interaction (2013) (doi:10.1155/2013/931698).

Cinar, N. O. 2015. "Usability Evaluation of Mobile and Desktop Websites: A Study of Comparing Usability Evaluation Methodologies," Institute Of Middle East Technical University.

Fernandez, A., Insfran, E., and Abrahão, S. 2011. "Usability Evaluation Methods for the Web: A Systematic Mapping Study," Information and Software Technology (53:8), Elsevier B.V., pp. 789-817 (doi: 10.1016/j.infsof.2011.02.007).

Gómez, R. Y., Caballero, D. C., and Sevillano, J.-L. 2014. "Heuristic Evaluation on Mobile Interfaces: A New Checklist.," The Scientific World Journal (2014), p. 434326 (doi:10.1155/2014/434326).

Gulati, A., and Dubey, S. K. 2012. "Critical Analysis on Usability Evaluation Techniques," International Journal of Engineering Science and Technology (IJEST) (4:3), pp. 990-997.

Hermawan, M. A., Hidayat, N., and Setiawan, B. D. 2017. "Sistem Optimasi Rute Tempat Wisata Kuliner Di Malang Menggunakan Algoritma Bee Colony," Jurnal Pengembangan Teknologi Informasi Dan Ilmu Komputer (1:3), pp. 215-223.

Hinderks, A., Schrepp, M., and Thomaschewski, J. 2018. "A Benchmark for the Short Version of the User Experience Questionnaire," WEBIST 2018 - Proceedings of the 14th International Conference on Web Information Systems and Technologies (Webist), pp. 373-377 (doi:10.5220/0007188303730377).

Hussain, A., and Mkpojiogu, E. O. C. 2016. "Usability Evaluation Techniques in Mobile Commerce Applications: A Systematic Review," AIP Conference Proceedings (1761) (doi:10.1063/1.4960889).

Jaspers, M. W. M. 2009. "A Comparison of Usability Methods for Testing Interactive Health Technologies: Methodological Aspects and Empirical Evidence," International Journal of Medical Informatics (78:5), pp. 340-353 (doi:10.1016/j.ijmedinf.2008.10.002).

Khajouei, R., Zahiri Esfahani, M., and Jahani, Y. 2017. "Comparison of Heuristic and Cognitive Walkthrough Usability Evaluation Methods for Evaluating Health Information Systems," Journal of the American Medical Informatics Association (24:e1), pp. e55-e60 (doi:10.1093/jamia/ocw100).

Kumar, R. 2019. “Zomato App — UX Redesign.” (https://uxplanet.org/zomato-app-ux-redesign- 
64237467b121).

Lewis, J. R., and Sauro, J. 2018. "Item Benchmarks for the System Usability Scale," Journal of Usability Studies (13:3), pp. 158-167. (https://uxpajournal.org/wpcontent/uploads/sites/8/pdf/JUS_Lewis_May2018.pdf).

Liang, J., Xian, D., Liu, X., Fu, J., Zhang, X., Tang, B., and Lei, J. 2018. "Usability Study of Mainstream Wearable Fitness Devices: Feature Analysis and System Usability Scale Evaluation," JMIR MHealth and UHealth (6:11) (doi:10.2196/11066).

Mahatody, T., Sagar, M., and Kolski, C. 2010. "State of the Art on the Cognitive Walkthrough Method, Its Variants and Evolutions," International Journal of Human-Computer Interaction (26:8), pp. 741-785 (doi:10.1080/10447311003781409).

Martins, A. I., Rosa, A. F., Queirós, A., Silva, A., and Rocha, N. P. 2015. "European Portuguese Validation of the System Usability Scale (SUS)," Procedia Computer Science (67:Dsai), Elsevier Masson SAS, pp. 293-300 (doi:10.1016/j.procs.2015.09.273).

Paramitha, D. A. T., Cholissodin, I., and Dewi, C. 2019. "Prediksi Rating Otomatis Berdasarkan Review Restoran Pada Aplikasi Zomato Dengan Menggunakan Extreme Learning Machine (ELM)," Jurnal Pengembangan Teknologi Informasi Dan Ilmu Komputer (Vol.3, No.:5), pp. 4687-4693.

Parne, S. R. 2010. “Android Application of Restaurant Finder," Kansas State University.

Rahadiasta, R. I., Wijoyo, S. H., and Az-Zahra, H. M. 2019. "Evaluasi User Experience Pada Game FORTNITE MOBILE Menggunakan Metode Enhanced Cognitive Walkthrough," Jurnal Pengembangan Teknologi Informasi Dan Ilmu Komputer (3:9), pp. 9114-9123.

Salunkhe, P., and Singh, N. 2019. "Zomato - Business Model and Use of M-Commerce," Journal of the Gujarat Research Society (21:14), pp. 243-254.

Satapathy, S. C., Udgata, S. K., and Biswal, B. N. 2014. "Proceedings of the International Conference on Frontiers of Intelligent Computing: Theory and Applications (FICTA) 2013," Advances in Intelligent Systems and Computing (247), pp. 535-543 (doi:10.1007/978-3-319-02931-3).

Scholtes, M., Noll, K., Shrabi, K., and Gross, V. 2020. "Comparison of Formative Evaluation Methods in the Usability Process on the Example of a Medical App," in Proceedings of the 14th Health Informatics Meets Digittal Health Conference, G. Schreier, D. Hayn, and A. Eggerth (eds.), Amsterdam: IOS Press, pp. 101-107. (doi:10.3233/SHTI200081).

Schrepp, M. 2019. "User Experience Questionnaire Handbook." (https://www.ueqonline.org/Material/Handbook.pdf).

Schrepp, M., Hinderks, A., and Thomaschewski, J. 2017. "Design and Evaluation of a Short Version of the User Experience Questionnaire (UEQ-S)," International Journal of Interactive Multimedia and Artificial Intelligence (4:6), p. 103 (doi:10.9781/ijimai.2017.09.001).

Sharfina, Z., and Santoso, H. B. 2017. "An Indonesian Adaptation of the System Usability Scale (SUS)," in 2016 International Conference on Advanced Computer Science and Information Systems, ICACSIS 2016, pp. 145-148 (doi:10.1109/ICACSIS.2016.7872776).

Sharma, K., and Abdul Waheed, K. 2018. "Consumption of Online Food App Services : An Exploratory Study among College Students in Dubai," Middle East Journal of Business (13:4), pp. 4-11 (doi: 10.5742/mejb.2018.93500).

Shitkova, M., Holler, J., Heide, T., Clever, N., and Becker, J. 2015. "Towards Usability Guidelines for Mobile Websites and Applications," Proceedings of the 12th International Conference on Wirtschaftsinformatik (WI 2015), pp. 1603-1617.

Sihombing, O., Sihombing, S., Pasaribu, M. L., Kris, R., and Saragih, D. 2020. "Website Rekomendasi Tempat Kuliner Dengan Metode Social Trust Path," SAINTEK (Jurnal Sains Dan Teknologi) (3:1), pp. 1-6.

Stone, M. J., Migacz, S., and Wolf, E. 2019. "Beyond the Journey: The Lasting Impact of Culinary Tourism Activities," Current Issues in Tourism (22:2), Taylor \& Francis, pp. 147-152 (doi: 10.1080/13683500.2018.1427705).

Suciyono, N., Anwar, D. S., and Setyawan, E. 2019. "Pencarian Wisata Kuliner Terdekat Dengan Menggunakan Metode LBS (Location Based Service) Berbasis Web Mobile Di Kota Tasikmalaya," Jurnal Voice of Informatics (8:1), pp. 67-76.

Ulinuha, H. R., Utami, E., and Sunyoto, A. 2020. "Evaluasi User Experience Pada Game Pes 2020 Menggunakan Metode Cognitive Walkthrough," Respati (15:2), pp. 45-52.

Unrau, R., and Kray, C. 2019. "Usability Evaluation for Geographic Information Systems: A Systematic 
Literature Review," International Journal of Geographical Information Science (33:4), Taylor \& Francis, pp. 645-665 (doi:10.1080/13658816.2018.1554813).

\section{How to cite:}

Ambarwati, P., Mustikasari M. 2021. "Usability Evaluation of the Restaurant Finder Application Using Inspection and Inquiry Methods," Jurnal Sistem Informasi (Journal of Information System) (17:2), pp. 1-17. 